\title{
Identification of novel growth factor-responsive genes in neuroendocrine gastrointestinal tumour cells
}

\author{
E Hofsli, I,2, L Thommesen', F Yadetie', M Langaas ${ }^{3}$, W Kusnierczyk ${ }^{4}$, U Falkmer ${ }^{1,2}$, AK Sandvik' and \\ A Laegreid'
}

'Department of Cancer Research and Molecular Medicine, Faculty of Medicine, Norwegian University of Science and Technology, Medisinsk Teknisk Forskningssenter, Trondheim N-7489, Norway; ${ }^{2}$ Oncology Unit, St Olavs Hospital HF, Trondheim, Norway; ${ }^{3}$ Department of Mathematical Sciences, Norwegian University of Science and Technology, Trondheim, Norway; ${ }^{4}$ Department of Computer and Information Science, Norwegian University of

Science and Technology, Trondheim, Norway

Targeting growth-regulatory pathways is a promising approach in cancer treatment. A prerequisite to the development of such therapies is characterisation of tumour growth regulation in the particular tumour cell type of interest. In order to gain insight into molecular mechanisms underlying proliferative responses in neuroendocrine (NE) gastrointestinal (Gl) tumours, we investigated gene expression in human carcinoid BON cells after exposure to gastrin, hepatocyte growth factor (HGF), pituitary adenylate cyclaseactivating polypeptide or epidermal growth factor. We particularly focused on gastrin- and HGF-induced gene expression, and identified 95 gastrin- and IOI HGF-responsive genes. The majority of these genes are known mediators of processes central in tumour biology, and a number of them have been associated with poor prognosis and metastasis in cancer patients. Furthermore, we identified 12 genes that were regulated by all four factors, indicating that they may be universally regulated during NE GI tumour cell proliferation. Our findings provide useful hypotheses for further studies aimed to search for new therapeutic targets as well as tumour markers in NE Gl tumours.

British Journal of Cancer (2005) 92, I506-1516. doi:I0.1038/sj.bjc.6602535 www.bjcancer.com

(c) 2005 Cancer Research UK

Keywords: neuroendocrine tumours; growth factors; proliferation; gene expression profiling; gastrin; hepatocyte growth factor

Carcinoids are the most common type of neuroendocrine (NE) tumours found in the gastrointestinal (GI) system (Öberg, 2000; Modlin et al, 2003). Although rare, with an incidence of approximately $1-2 / 100000$ per year (Öberg, 2000; Modlin et al, 2003), the prevalence is high because of their usually welldifferentiated nature and relatively slow growth rate. However, some patients have highly aggressive tumours leading to early death, while many of those living for several years have debilitating symptoms due to hypersecretion of biogenic amines and hormones. Surgery is the only potentially curative treatment, but since distant metastasis or regional disease are often present at the time of diagnosis, cure is most often not possible (Modlin et al, 2003). Thus, new therapeutic options are needed. Targeting key growth-regulatory pathways is a promising approach in cancer treatment (Behe and Behr, 2002; Yee, 2002; Sridhar et al, 2003; Ranson, 2004; Jiang et al, 2005), and requires a thorough knowledge of molecular mechanisms involved in growth regulation of various tumour cell types.

The amidated form of the peptide hormone gastrin is a wellknown regulator of gastric acid secretion and GI mucosal growth

*Correspondence: Dr E Hofsli, Department of Cancer Research and Molecular Medicine, Faculty of Medicine, Norwegian University of Science and Technology, Medisinsk Teknisk Forskningssenter, Trondheim N-7489, Norway; E-mail: eva.hofsli@ntnu.no

Received 28 October 2004; revised 23 February 2005; accepted 28 February 2005 and organisation (Waldum et al, 1995; Dockray et al, 2001, 2005). In addition, there is abundant evidence to suggest that gastrin may play an important role in tumour biology, as it is shown to regulate tumour cell growth (Dockray et al, 2001, 2005), and stimulate tumour cell invasion (Kucharczak et al, 2001) as well. Furthermore, hypergastrinaemia is associated with the occurrence of gastric enterochromaffin-like (ECL) cell carcinoid tumours (Waldum et al, 1995; Dockray et al, 2001, 2005; Richards et al, 2004) and with an increased risk of gastric and colorectal carcinoma (Dockray et al, 2001), indicating a role also in carcinogenesis. The biological actions of amidated gastrin are exerted through highaffinity binding to the gastrin/cholecystokinin B (CCK2) receptor (Denyer et al, 1994). This receptor has been shown to be coexpressed with gastrin in several GI tumour cell lines (Watson et al, 1998) and in human gastric carcinoids (Smith et al, 1998), indicating the existence of an autocrine gastrin growth-stimulatory loop. Interestingly, progress is being made in the development of CCK2 receptor targeting peptides for staging and therapy of human tumours (over)expressing this receptor (Behe and Behr, 2002).

Hepatocyte growth factor (HGF)/scatter factor was originally described as a factor promoting growth and scattering of multiple myeloma cells (Børset et al, 1996; Maulik et al, 2002). It is now clear that HGF exerts pleiotropic effects in a wide variety of tumour cells, where binding of HGF to its tyrosine kinase receptor c-Met promotes scattering, proliferation, angiogenesis, enhanced cell motility, invasion and metastasis (Maulik et al, 2002). However, its role in NE GI tumour cell biology is not yet defined. 
The same is true concerning the pleiotropic hormone pituitary adenylate cyclase-activating polypeptide (PACAP), which is known to regulate proliferation, differentiation and apoptosis in a number of malignant cells (Sherwood et al, 2000). However, PACAP and its various receptor forms have been found expressed in human NE tumours such as pheochromocytomas and neuroblastomas (Reubi et al, 2000; Sherwood et al, 2000), and PACAP has been found to modulate rat gastric ECL cell proliferation (Läuffer et al, 1999), indicating a possible role of PACAP in NE GI tumour cell biology as well.

Targeting the epidermal growth factor (EGF) receptor has emerged as a promising approach in the treatment of various types of cancers (Sridhar et al, 2003; Ranson, 2004). The EGF receptor is found (over)expressed in various human NE tumours (Nilsson et al, 1995; Wulbrand et al, 1998; Peghini et al, 2002), including GI carcinoids. More recently, the EGFR tyrosine kinase inhibitor gefitinib has been shown to inhibit growth of various NE GI tumour cells, including human carcinoid BON cells (Höpfner et al, 2003). The establishment of the BON cell line has been a major contribution to the study of growth regulation of NE GI tumours (Evers et al, 1991). Both serotonin (Ishizuka et al, 1992) and insulin-like growth factor (IGF)-1 (von Wichert et al, 2000) have been shown to act as autocrine regulators of growth of BON cells, while nerve growth factor (Bold et al, 1995) and basic fibroblast growth factor (FGF) stimulate growth in a nonautocrine manner (Townsend et al, 1993).

Various growth factor receptors are attractive targets for novel treatment approaches in NE GI tumour disease. In the present study, we employ transcript profiling to examine molecular mechanisms underlying proliferative responses in BON carcinoid tumour cells after exposure to gastrin, HGF, EGF and PACAP. By this approach, we identify a number of genes not previously known to be regulated by these growth factors and discuss the relevance of some of them as candidates for further studies in the search for new therapeutic targets in NE GI tumours.

\section{MATERIALS AND METHODS}

\section{Cell lines}

Human pancreatic carcinoid BON cells (Evers et al, 1991) were a generous gift from Professor Kjell Öberg, Department of Medical Sciences, Uppsala University Hospital, Uppsala, Sweden, and were grown in a $1: 1$ composition of Dulbecco's modified Eagle's medium (Gibco-BRL, Life Technologies, Paisley, Scotland) and RPMI 1640 medium (Gibco), containing $2 \mathrm{gl}^{-1}$ glucose, $10 \mathrm{U} \mathrm{ml}^{-1}$ penicillin/streptomycin (Gibco) and $10 \%$ heat-inactivated foetal calf serum (FCS) (Biological Industries, Beit Haemek, Israel). The colon carcinoma LoVo cell line was obtained from the American Type Culture Collection (ATCC, Manassas, VA, USA), and grown in RPMI 1640 medium containing $10 \%$ FCS, 2 mM L-glutamine, $4.5 \mathrm{gl}^{-1}$ glucose and $10 \mathrm{U} \mathrm{ml}^{-1}$ penicillin/streptomycin.

\section{Reagents}

Heptadecapeptide-amidated gastrin and forskolin were obtained from Sigma (St Louis, MO, USA). Hepatocyte growth factor was a kind gift from Professor Magne Børset, Department of Cancer Research and Molecular Medicine, Norwegian University of Science and Technology, Trondheim, Norway. Recombinant EGF was purchased from Biomedical Technologies (Stoughton, MA, USA), and PACAP-38 from Bachem (Bobendorf, Switzerland).

\section{Proliferation}

Proliferation rate was determined by measuring DNA synthesis using the Cell proliferation ELISA BrdU (5-bromo-2'-deoxyuridine) kit (Roche Applied Science, Mannheim, Germany). A total of 2 or $4 \times 10^{3}$ BON cells were seeded out in 96-well microtitre plates in serum-containing medium. After $24 \mathrm{~h}$, the cells were washed once with serum-free medium and then treated with various growth factors for $24 \mathrm{~h}$. Incorporation of $\mathrm{BrdU}$ was measured as described previously (Hofsli et al, 2002).

\section{Radioimmunoassays (RIAs)}

For detection of gastrin, BON cells were grown to confluence in six-well tissue culture plates and serum starved for $24 \mathrm{~h}$ in a volume of $1.2 \mathrm{ml}$, before the medium was collected, and cell lysates prepared by lysis in $400 \mu \mathrm{l}$ distilled water. Samples were kept frozen at $-80^{\circ} \mathrm{C}$ before amidated gastrin was measured using an RIA method as described previously (Kleveland et al, 1985).

\section{Detection of c-Met, CCK2 and $\mathrm{PAC}_{1}$ receptor mRNA}

Total RNA $(2 \mu \mathrm{g})$ from BON cells was reverse transcribed $\left(42^{\circ} \mathrm{C} /\right.$ $60 \mathrm{~min}$ ) in a volume of $20 \mu \mathrm{l}$ using $M u l \mathrm{~V}$ reverse transcriptase (RT) (Roche Applied Science). A measure of $2 \mu$ l of a $1: 3$ dilution of cDNA was then amplified in a $20 \mu$ l polymerase chain reaction (PCR) mix (Roche Applied Science) containing a final concentration of $1.6 \mathrm{mM} \mathrm{MgCl}_{2}, 500 \mathrm{~nm}$ of each primer, $1 \mathrm{U}$ of AmpliTaq Gold and $300 \mu \mathrm{m} \mathrm{dNTP.} \mathrm{PCR} \mathrm{amplifications} \mathrm{were} \mathrm{run} \mathrm{for} 36$ cycles with annealing temperature of $58^{\circ} \mathrm{C}$ (c-Met), $64^{\circ} \mathrm{C}$ (CCK2) and $56^{\circ} \mathrm{C}$ $\left(\mathrm{PAC}_{1}\right)$ receptor, respectively. The following primers were used (-S designates sense and -AS antisense primer): c-Met-S - $5^{\prime}$ TGGGAATCTGCCTGCGAA-3'; c-Met-AS, 5' -CCAGAGGACGACGCCAAA-3' (Børset et al, 1996); CCK2-S - 5'-AAC ACA AAC CAC AAC TGA-3'; CCK2-AS - $5^{\prime}$-AGG TCA AAC TAG GAG CAT-3' (GenBank accession no. reference sequence; NM 176875); and $\mathrm{PAC}_{1}-\mathrm{R}-\mathrm{S}-5^{\prime}$-CCC TGA GCT CTT CCG AAT-3'; $\mathrm{PAC}_{1}-\mathrm{R}-\mathrm{AS}-$ 5'-CCC ACA GGC ATC AAA GTA-3' (NM 001118).

\section{Treatment of cells and isolation of RNA}

For determination of growth factor-induced gene expression, BON cells were cultured in $75 \mathrm{~cm}^{2}$ culture flasks for $72 \mathrm{~h}$ until confluence was reached. After serum starvation for $24 \mathrm{~h}$, cells were exposed to either gastrin $(10 \mathrm{nM}), \mathrm{HGF}\left(100 \mathrm{ng} \mathrm{ml}^{-1}\right)$, EGF $\left(100 \mathrm{ng} \mathrm{ml}^{-1}\right)$ or PACAP (10 nM) for $6 \mathrm{~h}$. Untreated cells served as controls. RNA was isolated using the RNeasy Midi kit (Qiagen, Valencia, CA, USA), according to the manufacturer's instructions. RNA was examined for degradation by agarose gel electrophoresis with evaluation of the $18 \mathrm{~S}$ and $28 \mathrm{~S}$ ribosomal RNA bands and by use of Agilent 2100 Bioanalyzer (Agilent Technologies, Palo Alto, CA, USA). RNA concentration was assessed spectrophotometrically. The samples were kept frozen at $-80^{\circ} \mathrm{C}$ until further processing.

\section{Microarray hybridisation}

Arrays were manufactured by the Norwegian Microarray Consortium (www.mikromatrise.no/) using cDNA probes representing 2503 sequence-verified human genes (Research Genetics, Huntsville, AL, USA), including 1500 genes defined at that time in the NCI Oncochip selection. Of the 2503 genes, 2501 were printed in duplicates and two in quadruplicates. Additional information of cDNA clone preparation and printing are given in Nørsett et al (2004) and Yadetie et al (2003). Total RNA (1 $\mu \mathrm{g})$ from growth factor-treated and from untreated control cells (at time point zero) was reverse transcribed and labelled with Cy5- and Cy3-attached dendrimer, respectively, using the Genisphere 3DNA dendrimer kit (Genisphere, Montvale, NJ, USA) as described in the manufacturer's protocol and previously by us (Nørsett et al, 2004; Yadetie et al, 2003). Hybridised arrays were scanned separately at two wavelengths (532 and $633 \mathrm{~nm}$ ). 


\section{Microarray data analysis}

Image analysis was carried out with the Microarray Suite software version 2.1 (Scanalytics, Fairfax, VA, USA). All subsequent statistical analyses were performed using the statistical package R, (R Development Core Team, 2004). Preprocessing consisted of automatic removal of weak spots and removal of systematic errors by normalisation. Spots with background-corrected spot intensity lower than the local background intensity in at least one channel were excluded from the analysis. Intensity-based normalisation was performed using locally weighted scatterplot smoothing (Yang et al, 2002).

Differentially regulated genes for each of the four treatments (gastrin, HGF, EGF and PACAP) were identified in a two-step procedure for each gene separately. First, a linear mixed effects model was fitted to the normalised log ratios of each gene, with the microarray slide as a random effect to take into account the correlation between multiple spots of each gene on the same slide. The nlme-software presented in Pinheiro and Bates (2000) was used to fit the model, and to produce a $P$-value for each gene based on a $t$-test in the fitted linear mixed effects model. In this first step, genes with $P$-values below 0.05 were selected as potentially interesting genes. It is, however, well known that gene-specific variances estimated from small sample sizes are unstable. To avoid that small estimated variances dominate genes with small estimated effects, a ratio cutoff of 0.8 and 1.25 was used on the selected genes.

To check the robustness of our analyses, we also calculated $P$ values based on a moderated $t$-test, as implemented in the Limma $\mathrm{R}$ package of Smyth (2004). The moderated $t$-test is based on empirical Bayes analysis, and is equivalent to shrinkage (or expansion) of the estimated sample variances towards a pooled estimate, resulting in more stable inference when the number of microarray experiments is small. A similar effect was achieved using the ratio cutoff in our two-step procedure. Duplicate spotted genes were averaged before the moderated $t$-tests were performed. The results to be presented are based on the two-step procedure, but in addition the maximum $P$ - and $q$-values (Storey and Tibshirani, 2003) from the moderated $t$-tests on the selected gene sets are reported. The $q$-value of a gene can be interpreted as the minimum false discovery rate that can be attained when calling a given gene significantly differentially expressed. We have calculated a conservative version of the $q$-values, using 1 as the estimated proportion of genes truly not differentially expressed.

\section{Quantitative RT - PCR}

Verification of the microarray data was performed by quantitative RT - PCR analysis using the Smart Cycler (Cepheid, Sunnyvale, CA, USA). First, total RNA in a final concentration of $0.1 \mu \mathrm{g} \mu \mathrm{l}^{-1}$ was

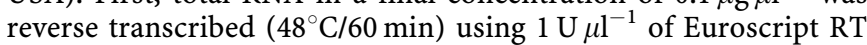
(Reverse Transcription Core Kit, Eurogentec, Seraing, Belgium). Undiluted cDNA $(2 \mu \mathrm{l})$ were then amplified for 30-40 cycles in a $25 \mu \mathrm{l}$ PCR mix (qPCR ${ }^{\mathrm{TM}}$ Core Kit for $\mathrm{Sybr}^{\mathrm{TM}}$ Green I-No ROX) (Eurogentec) containing a final concentration of $2.5 \mathrm{mM} \mathrm{MgCl}_{2}$ and $300 \mathrm{~nm}$ of each primer. Each cycle consisted of denaturing for $15 \mathrm{~s}$ at $95^{\circ} \mathrm{C}$, annealing for $15 \mathrm{~s}$ at $55^{\circ} \mathrm{C}$ and polymerisation for $30 \mathrm{~s}$ at $72^{\circ}$. The $C_{\mathrm{t}}$ value, defined as the number of cycles required to produce a detectable product above background fluorescence, was measured for each sample, and arbitrary units were calculated using a standard curve, which was run for each individual PCR analysis. The standard curves consisted of serial dilutions of cDNA of a sample or a control containing the highest amount of the specific gene analysed. A negative control without the cDNA template was run with every PCR assay, and contamination by genomic DNA was ruled out by performing PCR analysis on template where RT had been omitted in the RT reactions. Glyceraldehyde-3-phosphate dehydrogenase RT-PCR were run in parallel as control to monitor RNA integrity and to be used for normalisation. Specificity of each primer pair was confirmed by melting curve analysis and agarose gel electrophoresis. Table 1 shows the primer sequences and expected sizes of the PCR products.

\section{RESULTS}

\section{Gastrin-induced proliferation}

Since gastrin appears to be an important growth factor of various tumour cell types (Dockray et al, 2001, 2005; Richards et al, 2004), and since some gastric carcinoids have been shown to express the CCK2 receptor (Smith et al, 1998), we examined whether gastrin could affect growth of carcinoid tumour cells as well. As shown in Figure $1 \mathrm{~A}$, gastrin induced proliferation of BON cells in a dosedependent manner. A maximum 1.7-fold increase was seen, which was comparable to that induced by FCS (1.4). To explore a possible role of gastrin as an autocrine growth factor of BON cells, we measured the gastrin protein levels in cell lysates and in conditioned medium. Our finding that BON cells do not produce gastrin themselves (detection limit in our assay is $5 \mathrm{pg} \mathrm{ml}^{-1}$ ) is in agreement with immunohistochemical findings of Evers et al (1991).

Since there have been conflicting results as to the question whether BON cells express the CCK2 receptor (Evers et al, 1991; Kim et al, 1997), we analysed for its mRNA by RT - PCR analysis. The results clearly demonstrate that BON cells express CCK2 receptor mRNA (Figure 2). Although this finding does not necessarily mean that the CCK2 receptor protein is being expressed in BON cells, it indicates that the observed growthstimulatory effect of gastrin is mediated via this receptor. Together, our findings support the view that gastrin may act as a regulator of carcinoid tumour growth (Smith et al, 1998; Behe and Behr, 2002).

\section{HGF-, EGF- and PACAP-induced proliferation}

In order to further explore growth regulation of human NE GI tumour cells, we tested a panel of other factors known to affect cell growth of other tumour cell types. We here report the novel findings that HGF, EGF and PACAP all stimulate proliferation of carcinoid BON cells (Figure 1B-D). A maximum 2.4-fold increase in proliferation was seen after stimulation with $50 \mathrm{ng} \mathrm{ml}^{-1}$ of HGF. By RT - PCR analysis, BON cells were shown to express mRNA of the HGF receptor (c-Met) (Figure 2), indicating a possible role of HGF in controlling growth of carcinoids. This is perhaps not surprising, as an aberrant c-Met signalling, either caused by overexpression/mutation of c-Met or by coexpression of c-Met and HGF, has been found in a variety of other malignancies (Maulik et al, 2002). Only two studies have so far investigated c-Met expression in NE GI tumours. Wulbrand et al (1998) found the cMet mRNA expression frequencies to vary considerably, with the highest found in gastrinomas (33\%) and the lowest (11\%) in small intestine carcinoid tumours. In a gastrinoma study (Peghini et al, 2002), universal expression of c-Met mRNA was demonstrated in all 22 tumours investigated. Compared to normal pancreas, only a minority of the tumours (14\%) showed slight overexpression of cMet. Unlike findings in other tumour types (Maulik et al, 2002), cMet overexpression in these gastrinomas were not correlated with a more aggressive tumour behaviour. In conclusion, the present study indicates that the BON cell line could serve as a valuable experimental model to study molecular mechanisms involved in HGF-mediated responses in NE tumour cells.

Our finding that EGF stimulates growth of BON cells (Figure 1C) was somewhat surprising, since others did not find this effect in BON (Townsend et al, 1993). A maximum 1.6-fold increase was 
A
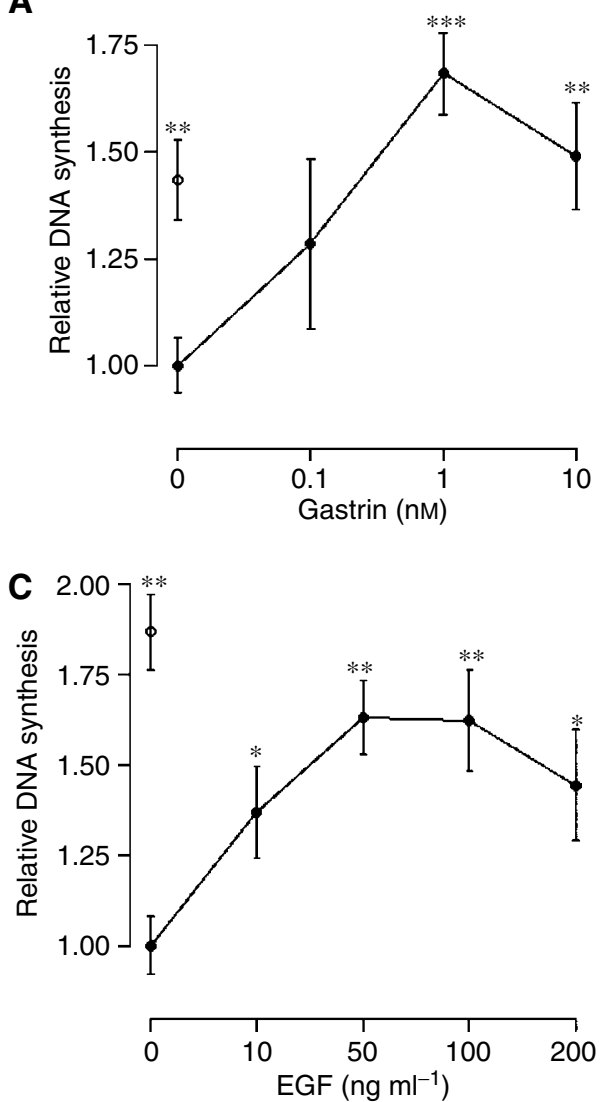
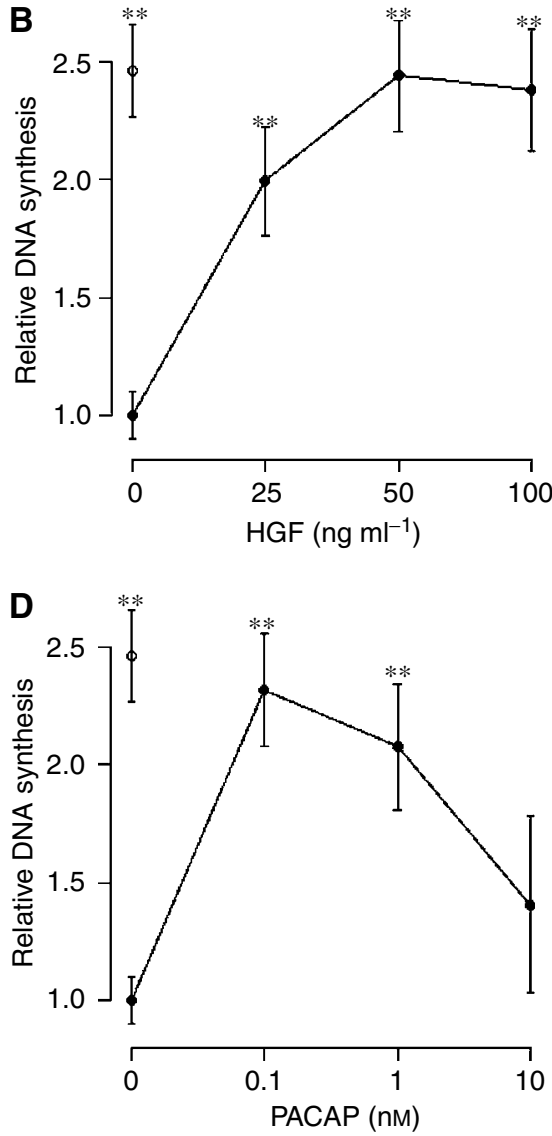

Figure I Growth factor-induced proliferation of BON cells. BON cells were stimulated for $24 \mathrm{~h}$ with gastrin $(\mathbf{A}), \mathrm{HGF}(\mathbf{B}), \mathrm{EGF}(\mathbf{C})$ or PACAP (D), with quadriplicate parallels per condition, and proliferation measured as BrdU incorporation. Results are shown as the mean value \pm s.e.m. of one representative experiment, and are expressed as relative values compared to untreated cells (control). Similar results were obtained in at least three other experiments. $* P \leqslant 0.01$. *** $P \leqslant 0.001$, $* * * P \leqslant 0.000$ I. $O$, proliferative effect of I0\% FCS. The statistical test used is an unpaired t-test.

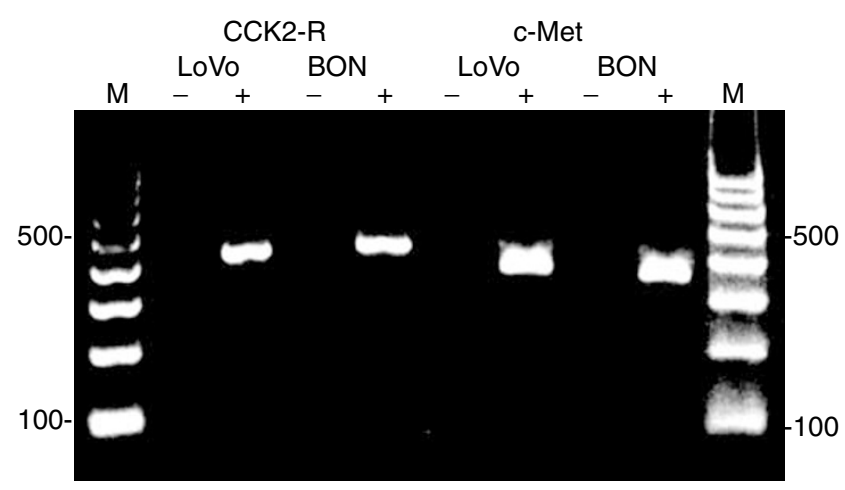

Figure 2 Expression of CCK2 receptor and HGF receptor (c-Met) in BON cells. RT-PCR analysis of total RNA was performed with $(+)$ or without ( - RT to rule out contamination of genomic DNA. PCR products were visualised in ethidium bromide-stained I.2\% agarose gels, and showed the expected sizes of $398 \mathrm{bp}$ (CCK2 receptor) and $395 \mathrm{bp}$ (c-Met), respectively. LoVo cells were used as a positive control for CCK2 receptor (Watson et al, 1998) and c-Met (Nabeshima et al, 1998). The results shown are representative of three independent experiments. M: $100 \mathrm{bp}$ DNA ladder molecular weight marker.

seen using either 50 or $100 \mathrm{ng} \mathrm{ml}^{-1}$ EGF. The discrepancy of results may relate to the fact that we used a more sensitive method for measurement of proliferation, or to phenothypic changes that may have occurred during cultivating of cells for years in vitro. Western blot analysis revealed a constitutive expression of phosphorylated (activated) EGF receptor in BON cells (data not shown), indicative of an aberrant EGF signalling in these cells. Recently, EGFR expression has in fact been demonstrated in BON cells (Höpfner et al, 2003), but BON cells were not found to express the EGFR mutation EGFRvIII, which is often observed in non-NE tumours.

Also, PACAP was found to enhance DNA synthesis in BON cells (Figure 1D). Both the concentration of 0.1 and $1 \mathrm{nM}$ PACAP increased the proliferation by a factor of 2.2. Only a weak increase was observed with $10 \mathrm{~nm}$ PACAP. By RT - PCR analysis, BON cells were found to express mRNA of the PACAP selective receptor $\mathrm{PAC}_{1}$, but not VIP/PACAP receptors (data not shown). This is in agreement with earlier findings showing that tumours located in the NE system appear to express predominantly the $\mathrm{PAC}_{1}$ receptor (Reubi et al, 2000). Furthermore, it is consistent with findings in this study showing that PACAP in the range of $0.1-10 \mathrm{~nm}$ induces proliferation of BON cells, and with those in a previous study from our group showing that PACAP at the same concentrations induces histamine release from ECL cells known to only possess $\mathrm{PAC}_{1}$ and not VIP/PACAP receptors (Sandvik et al, 2001). No previous studies have investigated the expression of PACAP and its receptors in carcinoids. Our assumption that PACAP could act as an important growth regulator of NE GI tumours is supported by the fact that PACAP has been found to modulate rat gastric ECL cell proliferation, a cell type which during malignant transformation gives origin to gastric carcinoid tumours (Läuffer et al, 1999). 


\section{Gastrin- and HGF-regulated genes}

Having established the proliferative responses to gastrin, HGF, EGF and PACAP in BON cells, we performed transcript profiling by cDNA microarray analysis in an effort to improve insight into molecular mechanisms underlying these responses. A pilot study where gene expression was analysed in BON cells treated with gastrin for $2,6,16$ or $24 \mathrm{~h}$ demonstrated that the number of differentially expressed genes was highest at $6 \mathrm{~h}$ (data not shown). We therefore used this time point for further microarray analysis. We particularly focused on gastrin- and HGF-induced gene expression for three reasons. First, there are reasons to believe that gastrin plays a role as a regulator of carcinoid tumour growth in vivo. Second, the novel finding that also HGF affects growth of carcinoid tumour cells is interesting considering the central role HGF plays as a growth regulator of other tumour cell types. Third, gastrin and HGF represent growth factors acting through two different main types of receptors: G-protein-coupled and tyrosin kinase receptors, respectively.

Among the 2503 genes analysed, inference was performed for 2050 genes, where the number of observations was at least 3. Using our two-step statistical procedure to identify differentially expressed genes, we identified 95 genes to be regulated by gastrin, of which 54 were up- and 41 were downregulated (Supplementary Data). Furthermore, we identified 101 genes to be regulated by HGF, of which 47 were up- and 54 downregulated (Supplementary Data). These results were compared to the use of the moderated $t$ tests using the Limma R package of Smyth (2004). The maximum Limma $P$-value for the 95 potentially gastrin-regulated genes was found to be 0.01 and the maximum $q$-value to be 0.17 . For the 101 potentially HGF-regulated genes, the maximum Limma $P$-value was 0.01 and the maximum $q$-value 0.12 . We have previously shown that the labelling method used in the present study results in compressed microarray ratios, but quantitative RT-PCR validation experiments performed here (Table 3) and previously (Yadetie et al, 2003; Nørsett et al, 2004) have been able to confirm the microarray data.

Based on information from the literature and from the LocusLink and SwissProt databases, the genes were grouped according to cellular processes in which they are likely to be

Table I Primer sequences of selected genes for confirmation studies

\begin{tabular}{llc}
\hline Gene & PCR products (bp) \\
\hline EPSI5 & S-5'-CTG TCC CAA ACC CTT TAC A-3' & 130 \\
& AS-5' AGA ATC CCA TCC ATA TAT CCA-3' & \\
IGFBPI & S-5'-GGA GGA CGG TTA ACT TGT AT-3' & 130 \\
& AS-5'-AAC AAC ATA TCC AGG TAC ATT-3' & \\
PIMI & S-5'-GGA GAC CCC AGA TAG GAC-3' & 125 \\
& AS-5'-GGA GAT AGG AAG CCA GAC TAC-3' & \\
RRM2 & S-5'-AGC AAG CGA TGG CAT AG-3' & 110 \\
& AS-5'-GTA TGT TTT CCA TGG CAA TाT-3' & \\
ATF4 & S-5'-GGA GAC CCC AGA TAG GAC TC-3' & 110 \\
& AS-5'-GAC TAC ACT GCT TAC GTT GCC-3' & \\
LAMRI & S-5'-TGA AAT TCC TCC TTG GTC ACT-3' & 120 \\
& AS-5'-CAT TTC CCG TGA ACA CCC-3' & \\
BTG & S-5'-CAA CTT TGC CAC AAT CAA TA-3' & 141 \\
& AS-5'-CTT TCC TTG TAC TTA ATT GGG-3' & \\
GAPDH S-5'-TCT GAC TTC AAC AGC GAC ACC-3' & 118 \\
& AS-5'-TGT TGC TGT AGC CAA ATT CGT-3' \\
\hline
\end{tabular}

$\mathrm{PCR}=$ polymerase chain reaction; $\mathrm{S}=$ sense; $\mathrm{AS}=$ antisense. involved. Since we were interested in processes that are likely to play a role in the context of cancer, we focused on cell proliferation, apoptosis, cell adhesion, cell motility and oncogenesis. Even though many genes may be involved in more than one process, each of the genes was grouped into only one category; this regarded to be most relevant for the response studied here (Table 2). Within these categories, we identified 27 genes that are regulated by both gastrin and HGF (Table 2a), 30 that are only regulated by gastrin (Table $2 \mathrm{~b}$ ), and finally, 25 that are only regulated by HGF (Table 2c). The remaining 38 gastrin- and 49 HGF-responsive genes were regarded to participate in other cellular processes, or to have unknown functions (all differentially expressed genes are shown in Supplementary Data). Of the 95 and 101 gastrin- and HGF-responsive genes, similar proportions were involved in cell proliferation $(23-24 \%)$, cell motility/adhesion $(15-16 \%)$ and in apoptosis $(4 \%)$. It was therefore interesting to note that for the process oncogenesis, the proportion of gastrinresponsive genes was twice as high $(16 \%)$ as the proportion of HGF-responsive genes (8\%). This may indicate that the oncogenic potential of gastrin in carcinoid cells is at least as high as that of HGF.

\section{Genes regulated by all growth factors}

In order to identify common growth factor-responsive genes, which may represent candidate genes of tumour growth regulation in general, we compared gene expression induced by gastrin, HGF, EGF and PACAP. In all, 12 genes were found to be significantly regulated $(\mathrm{P}<0.05$ from the $t$-test based on the linear mixed effects model in the first step of our two-step procedure) by all the four growth factors (Table 3), indicating that they may be universally regulated during NE GI tumour cell proliferation. However, it is to be noted that the concentration of PACAP $(10 \mathrm{nM})$ used in the gene expression analysis only induced a weak proliferative response in BON cells (Figure 1D). The common genes identified participate in various cellular processes, as four of them encode proteins known to be mediators of proliferation (EDN1, EGR3, ATF4 (activating transcription factor 4$), I L 2 R B)$, three encode proteins involved in adhesion (CCR1, CDH11 (cadherin-11), LAMA5 (laminin, alpha $5)$ ), two in metabolism (PCCA, PFKM), one in RNA splicing $(P P I G)$, and finally, two are involved in oncogenesis (CIN85, PIM1).

\section{Validation by real-time quantitative RT - PCR}

It is well known that data from microarray analysis need to be interpreted cautiously (Kothapalli et al, 2002). To validate the microarray results in this study, we performed real-time quantitative fluorescent RT - PCR analysis of seven selected genes using the same RNA samples from gastrin- and HGF-treated cells as those used in the microarray analysis. Concordant results were found for all the four upregulated genes tested (ATF4, LAMR1 (laminin receptor 1), BTG1, RRM2) (Table 4), while one (IGFBP1) out of three downregulated genes tested (EPS15, IGFBP1, PIM1) was confirmed to be differentially expressed (Table 4). The serine/ threonine kinase PIM1 proto-oncogene was, by RT-PCR analysis, shown to be slightly upregulated by gastrin, and markedly upregulated by HGF. In prostate cancer, the expression of the PIM1 protein has been shown to correlate with clinical outcome (Dhanasekaran et al, 2001), and the novel detection of this protooncogene in carcinoid tumour cells warrants further studies to explore its role as a potential prognostic marker also in NE GI tumours.

Our confirmatory rate of $71 \%$ underlines the need to verify microarray data by other methods, but our verification results seem to be in accordance with that of others (Kothapalli et al, 2002) and that previously shown by us (Nørsett et al, 2004; Yadetie et al, 2003). 
Table 2 Genes significantly $y^{a}$ regulated by (a) both gastrin and HGF, (b) gastrin and not by HGF and (c) HGF and not by gastrin

\section{Ratio $^{\text {c }}$}

Gene symbol

Gene name

Accession $^{b}$

Gastrin

HGF

(a) Both gastrin and HGF

Cell proliferation

Activating transcription factor 4

AA6002 17

Cyclin I

ANXAII

Annexin All

$\mathrm{MCM} 3$

Minichromosome maintenance deficient 3

AA434408

AA46505 I

NP

Nucleoside phosphorylase

STKI2

Serine/threonine kinase 12

IL2RB

Interleukin 2 receptor, beta

GNRHI

EPSI 5

Gonadotropin-releasing hormone I

LOC5 I 177

EGF receptor pathway substrate 15

SCYAI6

Small inducible cytokine subfamily A (Cys-Cys), member 16

AA455786

AA430382

AA07| 486

AA057156

AA043996

AA490223

AA490216

T58775

BCL2 antagonist/killer I

Apoptosis

BAKI

Hematopoietic cell-specific Lyn substrate I

$\mathrm{H} 52673$

AA424575

\subsection{3}

1.52

1.47

1.35

1.29

1.25

0.48

0.55

0.66

0.76

0.77

1.46

HCLSI

Lectin, galactoside-binding, soluble, 3 binding protein

Microtubule-associated protein IB

Laminin receptor I

Monokine induced by gamma interferon

Chemokine $(\mathrm{C}-\mathrm{C})$ motif receptor I

Cadherin II

Laminin, alpha 5

Integrin, alpha $\mathrm{V}$

AA485353

AA219045

AA629897

AAI 31406

AA03688I

AAl 36983

AA459519

LAMA5

Myeloid leukemia factor 2

AA029934

1.26

0.77

1.29

ITGAV

c-Cbl-interacting protein

AA480835

AA989257

AA464644

Gluatathione S-transferase theta

H998I3

Pim-I oncogene

GIMI

RABI 8, member RAS oncogene family

AA453663

AAI5682I

1.54

1.54

1.49

0.53

0.63

0.66

0.77

0.77

1.42

1.27

1.38

1.30

1.28

0.46

$$
0.57
$$

0.63

0.75
0.70

$\mathrm{RAB} \mid 8$

$\begin{array}{ll}1.30 & 1.40 \\ 1.31 & 1.26 \\ 1.29 & 1.31 \\ 1.25 & 1.35 \\ 0.75 & 0.50 \\ 0.79 & 0.75\end{array}$

Gene name

Accession $^{b}$

Gene symbol

\section{GF}

(b) Gastrin and not by HGF

Cell proliferation

BTGI

IL-8

EGR3

ERCC5

$\mathrm{MCM} 3$

FGFI

ETRIOI

RAD23A

CAMK2D

LIG3

HDAC2

Apoptosis

PPARG

LTBR

Ribonucleotide reductase $M 2$ polypeptide

B-cell translocation gene I

Interleukin 8

Early growth response 3

Excision repair crosscomplementing rodent repair deficiency, complementation group 5

Minichromosome maintenance deficient 3

Fibroblast growth factor I (acidic)

Immediate-early protein

RAD23 (C. cervisiae) homolog A

Calcium/calmodulin-dependent protein kinase (camkinase) II delta

Ligase III, DNA, ATP dependent

Histone deacetylase 2

AA 18735 I

N70463

AAI02526

R39III

N62586

AA455786

AAOI 5793

AA496359

AA476274

AA283023

AAI 49292

AA 127093

Ratio $^{c}$

A0885 I7

AA454646

1.59

1.57

1.46

1.46
1.45

1.44

1.35

1.30

1.27

1.26

1.26

0.61

0.72

Peroxisome proliferative-activated receptor, gamma

Lymphotoxin beta receptor

1.3

0.67

Cell adhesion/motility

RCN2

Reticulocalbin 2

Serine (or cysteine) proteinase inhibitor, member 5

CDH6 Cadherin 6

SYK

Spleen tyrosine kinase

Insulin-like growth factor binding protein I

|GFBP|

SCYA2

Small inducible cytokine A2

MMP7

Matrix metalloproteinase 7

AA598676

AA858026

AA421819

AA598572

AA233079

AA425102

AA031513

1.36

1.28

1.25

0.63

0.66

0.71

0.78

Oncogenesis

$\mathrm{HOXAI}$

Homeo box Al

SI00 calcium-binding protein A3
AA 173290

AA055242
1.33

1.29 
Table 2 (Continued)

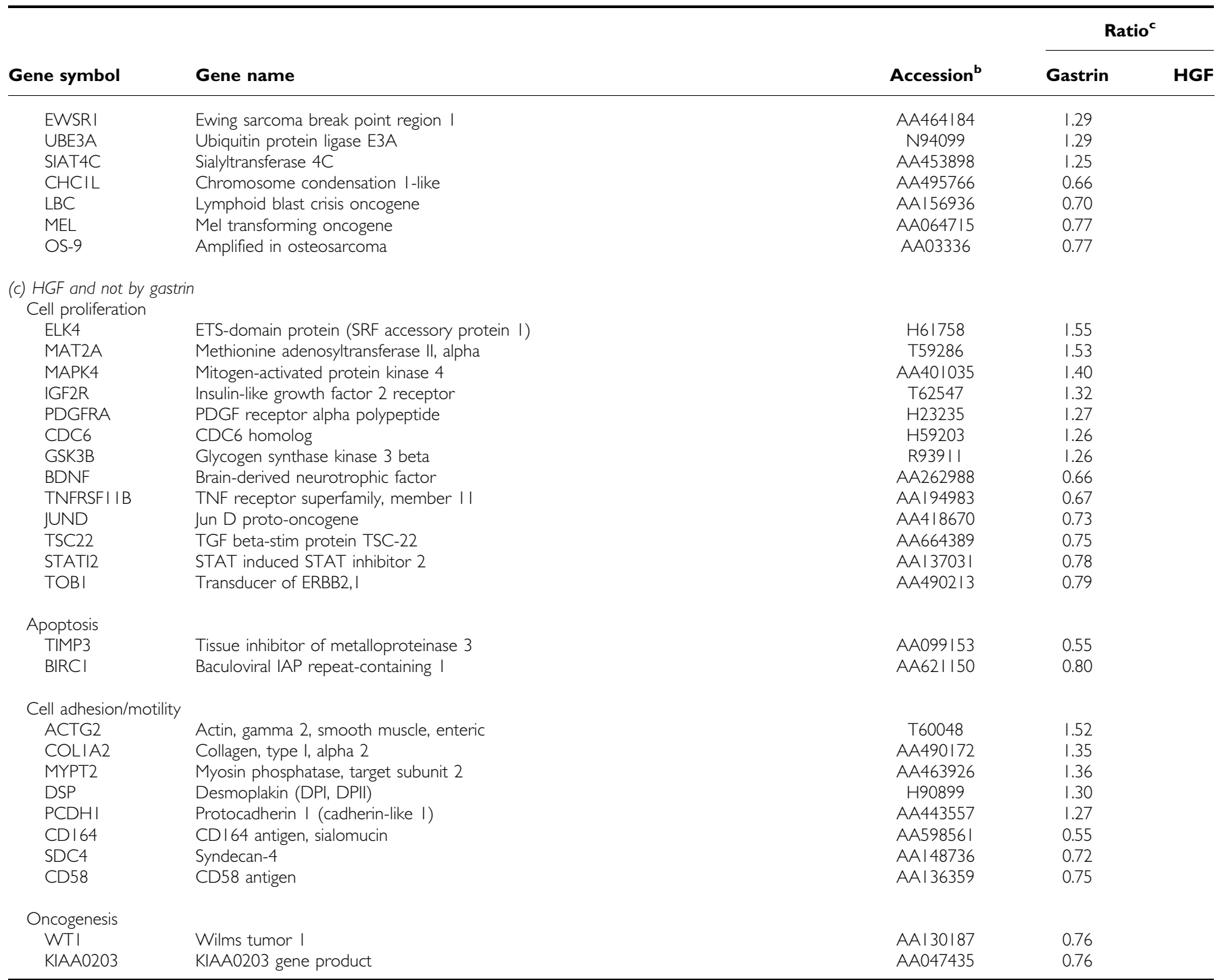

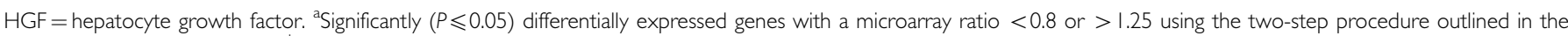
Materials and Methods section. ${ }^{b}$ GenBank accession number. Listed are genes with functions relevant in cancer biology. The remaining genes with other or unknown functions are listed in Supplementary Data. The gastrin data are based on samples from two biological experiments, of which one sample was hybridised once, and the other twice. The HGF data are based on samples from two biological experiments, which both were hybridised twice. "Microarray ratio (treated/untreated cells).

\section{DISCUSSION}

Growth factor-induced signalling impacts on many aspects of tumour biology. The results of this study contribute to an increased knowledge of molecular events underlying growth factor-induced proliferation of human NE GI tumour cells, by identifying a number of novel growth-responsive genes. Our study also sheds new lights into the biology of NE GI tumours, and provides candidate genes in the search for new therapeutic targets.

To the best of our knowledge, only a few of the growth factorresponsive genes identified in this study have earlier been shown to be regulated by the respective factors. However, the demonstration of differential expression of already known growth factorresponsive genes confirms the reliability of our results. In a study investigating the transcriptional response to $\mathrm{HGF}$ in mouse embryo liver cells, HGF was found to regulate a number of extracellular matrix proteins (Medico et al, 2001). Similar to the findings in that study, we confirmed the upregulation of the gene COL1A2 (collagen, type I, alpha), and the downregulation of LAMA 5 by HGF. Furthermore, gastrin was shown to upregulate the expression of interleukin-8 (IL-8), which has earlier been identified as a gastrin-regulated gene in rat gastric epithelial cells (Hiraoka et al, 2001). IL-8 has been shown to contribute to human cancer progression through its mitogenic, angiogenic and migratory action (Xie, 2001). In accordance with a recently published study performed using rat pheochromocytoma PC12 cells (Grumolato et al, 2003), we identify LAMR1 as a PACAP-responsive gene. Finally, tissue inhibitor of metalloproteinase 3 (TIMP3) is recognised as an HGF-responsive gene, as previously shown by Castagnino et al (1998).

Annotations of the genes reveal that the majority of the novel gastrin- and HGF-responsive genes seem to participate in processes relevant in the context of tumour biology. However, it has to be noted that cancer-related genes were well represented on 
Table 3 Genes significantly ${ }^{\mathrm{a}}$ regulated by all growth factors

\begin{tabular}{|c|c|c|}
\hline Gene symbol & Gene name & Accession $^{\mathbf{b}}$ \\
\hline \multicolumn{3}{|l|}{ Upregulated } \\
\hline EDNI & Endothelin I & $\mathrm{HII0O3}$ \\
\hline PCCA & $\begin{array}{l}\text { Propionyl coenzyme A carboxylase, } \\
\text { alpha polypeptide }\end{array}$ & AA608575 \\
\hline PPIG & Peptidyl-prolyl isomerase G & AA458502 \\
\hline CIN85 & c-Cbl-interacting protein & AA989257 \\
\hline EGR3 & Early growth response 3 & R39||I \\
\hline ATF4 & Activating transcription factor 4 & AA600217 \\
\hline \multicolumn{3}{|l|}{ Downregulated } \\
\hline IL2RB & Interleukin 2 receptor, beta & AA057I56 \\
\hline CCRI & Chemokine ( $\mathrm{C}-\mathrm{C}$ motif) receptor I & AA03688I \\
\hline $\mathrm{CDHII}$ & Cadherin 11 , type 2, OB-cadherin (osteoblast) & AAl36983 \\
\hline PFKM & Phosphofructokinase, muscle & AA099169 \\
\hline PIMI & Pim-I oncogene & AA453663 \\
\hline LAMA5 & Laminin, alpha 5 & AA459519 \\
\hline
\end{tabular}

${ }^{a}$ Genes significantly $(P<0.05)$ down- or upregulated by gastrin, HGF, EGF and PACAP using the first step of the two-step procedure outlined in the Materials and Methods section. ${ }^{b}$ GenBank accession number. The gastrin data are based on samples from two biological experiments, of which one sample was hybridised once, and the other twice. The HGF data are based on samples from two biological experiments, which both were hybridised twice.

Table 4 Verification of microarray data by quantitative RT-PCR analysis

\begin{tabular}{|c|c|c|c|}
\hline Gene & Treatment & PCR ratio ${ }^{a}$ & Microarray ratio ${ }^{b}$ \\
\hline \multirow[t]{2}{*}{ ATF4 } & Gastrin & 2.1 & 1.6 \\
\hline & HGF & 1.5 & 1.5 \\
\hline \multirow[t]{2}{*}{ BTGI } & Gastrin & 1.2 & 1.5 \\
\hline & HGF & 1.2 & 1.2 \\
\hline \multirow[t]{2}{*}{ RRM2 } & Gastrin & 1.2 & 1.7 \\
\hline & HGF & 1.0 & 1.2 \\
\hline \multirow[t]{2}{*}{ LAMRI } & Gastrin & 1.3 & 1.6 \\
\hline & HGF & 1.1 & 1.3 \\
\hline \multirow[t]{2}{*}{$|G F B P|$} & Gastrin & 0.9 & 0.7 \\
\hline & HGF & 0.8 & 0.8 \\
\hline \multirow[t]{2}{*}{ EPS 15} & Gastrin & 1.0 & 0.7 \\
\hline & HGF & NA & 0.6 \\
\hline \multirow[t]{2}{*}{ PIMI } & Gastrin & 1.8 & 0.8 \\
\hline & HGF & I.1 & 0.6 \\
\hline
\end{tabular}

RT-PCR = reverse transcriptase-polymerase chain reaction; HGF = hepatocyte growth factor; NA; not analysed. ${ }^{a} \mathrm{RNA}$ transcript level in arbitrary units was standardised by the level of GAPDH, and expressed as fold change in treated relative to untreated cells. RT -PCR analysis was performed with the same total RNA as used in the microarray experiments. PCR ratios calculated from analysis of one biological sample with either gastrin or HGF are shown. ${ }^{b}$ Corresponding microarray ratio for the same biological sample.

our arrays. In addition to IL-8, several other genes encoding proteins involved in cell proliferation were found to be regulated by gastrin and/or HGF. Gastrin was shown to upregulate the mRNA expression of the small M2 subunit of ribonucleotide reductase (RRM2), a rate-limiting enzyme in DNA synthesis and repair (Zhou and Yen, 2001). Several nonspecific inhibitors of ribonucleotide reductase are in fact already in clinical use as chemotherapeutic agents, and more recently, an antisense agent targeting RRM2 has shown potent antitumour activity against a variety of tumours (Lee et al, 2003). As far as we know, our study is the first one to demonstrate that polypeptide growth factors may affect the expression of RRM2, as also PACAP was shown to induce an upregulation.

Gastrin, HGF and PACAP were all shown to upregulate the expression of the highly conserved LAMR1 gene that plays a role in cell adhesion. This is interesting as there seems to be a correlation between the upregulation of LAMR1 in cancer cells, and their invasive and metastatic phenotype (Menard et al, 1998). Furthermore, gastrin was shown to downregulate the expression of spleen tyrosine kinase $(S Y K)$ gene. Reduced expression of this gene has been shown to be associated with distant metastasis and poor prognosis in breast cancer (Toyama et al, 2003), indicating that it may be a potential tumour suppressor and antimetastasis gene. Thus, downregulation of $S Y K$ may contribute to the assumed tumorigenic potential of gastrin. As elevated serum levels of the tumour-associated glycoprotein lectin, galactoside-binding, soluble, 3 binding protein (LGALS3BP) (Table $2 \mathrm{a}$ ) are often observed in cancer patients, and have been proven to be of prognostic value (Marchetti et al, 2002), the findings that both gastrin and HGF upregulate the expression of LGALS3BP justify studies exploring LGALS3BP expression in carcinoid tumour patients as well.

Gastrin and HGF affected the expression of several genes encoding proteins thought to be involved in apoptosis (Table $2 \mathrm{a}-$ c). As mentioned above, TIMP3 has earlier been recognised as an HGF-responsive gene, and here we demonstrate a marked downregulation of this proapoptotic gene after treatment with HGF. This is interesting as we know that loss of TIMP3 expression may enhance the invasive potential of certain tumours (Castagnino et al, 1998). Moreover, gastrin was shown to downregulate the expression of lymphotoxin beta receptor (LTBR). Activation of this receptor has been shown to induce apoptosis in some tumour cells (Browning et al, 1996), and thus a downregulation of its expression probably undermines its apoptotic effect.

It is noted that a considerably higher percentage of gastrin- than HGF-regulated genes were found to encode proteins considered to be involved in oncogenesis. Aberrant HGF/c-Met signalling has been well documented in a variety of human cancers (Maulik et al, 2002), and our results strengthen the view that also the gastrin signalling pathway could be involved in oncogenesis (Waldum et al, 1995; Dockray et al, 2001). An abberant expression of the homeo box A1 (HOXA1) gene is assumed to be the mechanism by which autocrine stimulation with human growth factor may result in oncogenic transformation, and it has recently been shown that forced expression of this gene in human mammary epithelial cells is sufficient for transformation of the cells (Zhang et al, 2003). Our finding that gastrin upregulates the expression of the HOXA1 gene indicates that this may be one mechanism by which gastrin could play a role in oncogenesis. Another mechanism could be through an upregulation of the mRNA of S100 calcium-binding protein A3 $(S 100 A 3)$, as this gene has been proposed to play a role in NE tumorigenesis (Stålberg et al, 2001). Additional support to such a view is the finding that gastrin downregulates the expression of the chromosome condensation 1-like $(C H C 1 L)$ gene. This gene has recently been proposed to be a candidate gene for prostate carcinogenesis (Latil et al, 2003).

Crosstalks between various growth factor systems are a wellknown phenomenon, and underline the complexity of tumour growth control. Gastrin has previously been shown to enhance the expression of both HGF (Konturek et al, 2003) and heparinbinding EGF-like growth factor (Dockray et al, 2001). In the present study, links to the IGF system were observed. This is of particular interest since IGF-1 is known to act as an autocrine growth factor of BON cells (von Wichert et al, 2000). Gastrin was shown to downregulate the expression of the IGFBP-1 (Tables $2 \mathrm{~b}$ and 4). IGFBP-1 is known to neutralise the actions of IGF-1, but in addition, it exerts independent actions as it inhibits breast cancer cell motility and growth by itself (Zhang and Yee, 2002). In fact, in 
breast cancer several strategies are currently being exploited using the IGF system as a biological target (Yee, 2002). Thus, a downregulation of IGFBP1 by gastrin may be one mechanism whereby gastrin promotes tumour growth and invasion. Another link to the IGF system was also noted, as HGF was shown to upregulate the expression of the IGF receptor 2 (IGFR2). Our data also indicate connections to other growth factor systems, as gastrin was shown to upregulate the expression of acidic fibroblast growth factor 1 (FGF1), while both gastrin and HGF were shown to decrease the expression of EGF receptor pathway substrate 15 (EPS15). HGF also increased the expression of PDGF receptor alpha polypeptide (PDGFRA), while PACAP was shown to upregulate the expression of the HGF-receptor c-Met.

PACAP was shown to induce a rather strong upregulation of IL8. This is similar to gastrin, which also acts through a G-proteincoupled receptor. In contrast, no regulation was seen after treatment with the tyrosine kinase-acting ligands HGF and EGF. A similar pattern was observed with regard to RRM2 expression, as the tyrosine kinase receptor-activating ligands HGF and EGF did not affect the expression of RRM2, while gastrin and PACAP upregulated RRM2 RNA levels.

One objective of this study was to identify genes that were regulated by all four growth factors, since such genes could possibly be regarded as universally regulated during tumour cell proliferation, and thus assumed to be of particular interest in the search for new drug targets. In all, 12 genes fulfilled the criteria, indicating that these genes may play a central role in NE GI tumour cell proliferation. Gastrin, HGF, EGF and PACAP were all shown to increase strongly the mRNA of ATF4, a member of the ATF/CREB family of mammalian transcription factors found to be expressed in all tissues examined so far (Hai and Hartman, 2002). Heregulin, a combinatorial ligand for EGFR 3 and 4, has earlier been found to upregulate ATF4 mRNA as well as ATF4 protein in human cancer cells (Talukder et al, 2000). Together, this indicates that ATF4 could play a central role in the mechanisms of tumour growth regulation in general.

Another interesting feature observed with all four growth factors was marked downregulation of the beta chain of the interleukin 2 receptor $(I L 2 R B)$. IL2 is known to inhibit proliferation and growth of various cancer cells (Casana et al, 2002), and thus a downregulation of a subunit of its receptor may be one additional mechanism whereby growth factors in general promote growth. All four growth factors were shown to downregulate the expression of CDH11. This has previously been shown to be the case also after treatment with transforming growth factor- $\alpha$ (Zhou and Skalli, 2000). As CDH11-overexpressing osteosarcoma cells have been found to exhibit a marked reduction in their ability to form pulmonary metastasis (Kashima et al, 2003), a downregulation of CDH11 may be one mechanism by which growth factors contribute to tumour progression. Finally, all growth factors were shown to downregulate the expression of LAMA5, which is interesting as a reduced level of LAMA5 has been shown to be associated with an increased tendency to develop lymph node metastasis in nonsmall-cell lung cancer (Akashi et al, 2001).

Our data showing that all four growth factors analysed may induce the expression of genes known to impact on many aspects of cancer indicate that these factors may play an important role in the establishment, growth and metastases of NE GI tumours, and that targeting their receptors, signalling pathways or secondary gene expression may be a possible way to stop or delay growth of such tumours. As mentioned above, targeting the EGF system has already become an established treatment modality in some types of tumours (Sridhar et al, 2003; Ranson, 2004), and has been shown to inhibit growth of NE GI tumour cells (Höpfner et al, 2003). Similarly, the pivotal role that HGF seems to play in cancer has led to the preclinical development of many types of targeting drugs, including antagonists, which compete with binding to the receptor, antibodies, which block the receptor, small-compound tyrosin kinase inhibitors, or other strategies that target downstream signals or secondary gene expression (Jiang et al, 2005).

In light of the fact that tumour growth in vivo is most often influenced by many different growth factors, either in a paracrine, autocrine or systemic manner, our identification of genes that are regulated by more than one factor in NE GI tumour cells may be of particular interest with regard to intervention of NE tumour disease. In addition, the demonstration in this paper of crosstalks between various growth factor systems strengthens the view that it probably will be more efficient to target more than one growth systems, as more recently has been shown in NE medullary thyroid cancer preclinical models (Ezzat et al, 2005). Our identification of ATF4 as a common inducible growth factor gene may indicate that silencing of this gene, for example, by use of siRNAs or antisense technology, may be an interesting approach to further study. Furthermore, the demonstration that gastrin and PACAP, similar to tumour microenvironment factors such as hypoxia, acidosis and nitric oxide (Xie, 2001), regulate IL-8 expression underline the need to further investigate the use of IL8-neutralising antibodies, IL-8 receptor blockers or IL-8 gene silencing approaches in the treatment of NE GI tumours. Moreover, LAMR1, also known as ribosomal protein SA, turns out to be an interesting candidate for further studies as both gastrin and HGF were shown to upregulate its expression. To the best of our knowledge, our study is the first to report LAMR1 expression in NE tumour cells.

In conclusion, by identifying a number of growth factorresponsive genes in human NE GI tumour cells, we have shed new light into the molecular mechanisms involved in growth control of these cells. Such knowledge is essential in order to design studies aimed to evaluate functional aspects of candidate genes. Although caution is advisable in the interpretation of microarray expression data, we believe that our results provide suggestions for further studies in the effort to identify new therapeutic targets as well as new markers of NE GI tumours.

\section{ACKNOWLEDGEMENTS}

This work was supported by EXTRA funds from the Norwegian Foundation for Health and Rehabilitation, The Norwegian Cancer Society, The Norwegian Research Council and the Cancer Fund at the St Olavs Hospital HF, Trondheim. We gratefully acknowledge the advice given by Dr Michael Bittner and Dr Paul Meltzer at the NHGRI, NIH, Bethesda MD, USA to establish the microarray method. Eli Helge, Sylvia Nome Kvam and Anne Kristensen provided excellent technical assistance.

Supplementary Information accompanies the paper on British Journal of Cancer website (http://www.nature.com/bjc)

\section{REFERENCES}

Akashi T, Ito E, Eishi Y, Koike M, Nakamura K, Burgeson RE (2001) Reduced expression of laminin alpha 3 and alpha 5 chains in non-small cell lung cancers. Jpn J Cancer Res 92: 293-301
Behe M, Behr T (2002) Cholecystokinin-B (CCK-B)/gastrin receptor targeting peptides for staging and therapy of medullary thyroid cancer and other CCK-B receptor expressing malignancies. Biopolymer 66: 399-418 
Bold RJ, Ishizuka J, Rajaraman S, Perez-Polo R, Townsend CM, Thompson JC (1995) Nerve growth factor as a mitogen for a pancreatic carcinoid cell line. J Neurochem 64: $2622-2628$

Børset M, Lien E, Espevik T, Helseth E, Waage A, Sundan A (1996) Concomitant expression of hepatocyte growth factor/scatter factor and the receptor c-MET in myeloma cell lines. J Biol Chem 271: $24655-24661$

Browning JL, Miatkowski K, Sizing I, Griffiths D, Zafari M, Benjamin CD, Meier W, Mackay F (1996) Signaling through the lymphotoxin beta receptor induces the death of some adenocarcinoma tumor lines. J Exp Med 183: $867-878$

Casana PH, Hernandez H, Arana MJ (2002) Interleukin-2 inhibits proliferation of HPV-associated tumor cells and halts tumor growth in vivo. Biochem Biophys Res Commun 299: 818-824

Castagnino P, Soriano JV, Montesano R, Bottaro DP (1998) Induction of tissue inhibitor of metalloproteinases- 3 is a delayed early cellular response to hepatocyte growth factor. Oncogene 17: 481-492

Denyer J, Gray J, Wong M, Stolz M, Tate S (1994) Molecular and pharmacological characterization of the human CCKB receptor. Eur J Pharmacol 268: 29-41

Dhanasekaran SM, Barrette TR, Ghosh D, Shah R, Varambally S, Kurachi K, Pienta KJ, Rubin MA, Chinnaiyan AM (2001) Delineation of prognostic biomarkers in prostate cancer. Nature 412: $822-826$

Dockray G, Dimaline R, Varro A (2005) Gastrin: old hormone, new functions. Pflügers Archiv Oct 5 [Epub ahead of print], doi: 10.1007/ s00424-004-1347-5

Dockray GJ, Varro A, Dimaline R, Wang T (2001) The gastrins: their production and biological activities. Annu Rev Physiol 63: 119-139

Evers BM, Townsend Jr CM, Upp JR, Allen E, Hurlbut SC, Kim SW, Rajaraman S, Singh P, Reubi JC, Thompson JC (1991) Establishment and characterization of a human carcinoid in nude mice and effect of various agents on tumor growth. Gastroenterlogy 101: 303-311

Ezzat S, Huang P, Dackiw A, Asa SL (2005) Dual inhibition of RET and FGFR4 restrains medullary thyroid cancer cell growth. Clin Cancer Res 11: $1336-1341$

Grumolato L, Elkahloun AG, Ghzili H, Alexandre D, Coulouarn C, Yon L, Salier J-P, Eiden LE, Fournier A, Vaudry H, Anouar Y (2003) Microarray and suppression subtractive hybridization analyses of gene expression in pheochromocytoma cells reveal pleiotropic effects of pituitary adenylate cyclase-activating polypeptide on cell proliferation, survival, and adhesion. Endocrinology 144: $2368-2379$

Hai T, Hartman MG (2002) The molecular biology and nomenclature of the activating transcription factor/cAMP responsive element binding family of transcription factors: activating transcription factor proteins and homeostasis. Gene 273: $1-11$

Hiraoka S, Miyazaki Y, Kitamura S, Toyota M, Kiyohara T, Shinomura Y, Mukaida N, Matsuzawa Y (2001) Gastrin induces CXC chemokine expression in gastric epithelial cells through activation of NF-kappaB. Am J PhysiolGastrointest Liver Physiol 281: G735-G742

Hofsli E, Thommesen L, Norsett K, Falkmer S, Syversen U, Sandvik AK, Laegreid A (2002) Expression of chromogranin A and somatostatin receptors in pancreatic AR42J cells. Mol Cell Endocrinol 194: 165-173

Höpfner M, Sutter AP, Gerst B, Zeitz M, Scherübl H (2003) A novel approach in the treatment of neuroendocrine gastrointestinal tumours. Targeting the epidermal growth factor receptor by gefitinib (ZD1839). $\mathrm{Br}$ J Cancer 89: $1766-1775$

Ishizuka J, Beauchamp RD, Townsend CM, Greeley Jr GH, Thompson JC (1992) Receptor-mediated autocrine growth-stimulatory effect of 5hydroxytryptamine on cultured human pancreatic carcinoid cell. J Cell Physiol 150: 1-7

Jiang WG, Martin TA, Parr C, Davies G, Matsumoto K, Nakamura T (2005) Hepatocyte growth factor, its receptor, and their potential value in cancer therapies. Crit Rev Oncol Hematol 53: 35-69

Kashima T, Nakamura K, Kawaguchi J, Takanashi M, Ishida T, Aburatani H, Kudo A, Fukayama M, Grigoriadis AE (2003) Overexpression of cadherins suppresses pulmonary metastasis in osteosarcoma in vivo. Int J Cancer 104: $147-154$

Kim HJ, Evers BM, Banker NA, Hellmich MR, Townsend Jr CM (1997) A functional in vitro model to examine signaling mechanisms in gastrinmediated human cell growth. J Gastrointest Surg 1: 69-77

Kleveland PM, Haugen SE, Waldum HL (1985) The preparation of bioactive ${ }^{125}$ I-gastrin, using Iodogen as oxidizing agent, and the use of this tracer in receptor studies. Scand J Gastroenterol 20: 569-576

Konturek PC, Kania J, Kukharsky V, Ocker S, Hahn EG, Konturek SJ (2003) Influence of gastrin on the expression of cyclooxygenase-2, hepatocyte growth factor and apoptosis-related proteins in gastric epithelial cells. J Physiol Pharmacol 54: 17-32

Kothapalli R, Yoder SJ, Mane S, Loughran Jr TP (2002) Microarray results: how accurate are they? BMC Bioinformatics 3: 22

Kucharczak J, Pannequin J, Camby I, Decaestecker C, Kiss R, Martinez J (2001) Gastrin induces over-expression of genes involved in human U373 glioblastoma cell migration. Oncogene 20: 7021-7028

Latil A, Chene L, Mangin P, Fournier G, Berthon P, Cussenot O (2003) Extensive analysis of the 13q14 region in human prostate tumor DNA analysis and quantitative expression of genes lying in the interval of deletion. Prostate 57: 39-50

Läuffer JM, Modlin IM, Hinoue T, Kidd M, Zhang T, Schmid SW, Tang LH (1999) Pituitary adenylate cyclase-activating polypeptide modulates gastric enterochromaffin-like cell proliferation in rats. Gastroenterology 116: $623-635$

Lee Y, Vassilakos A, Feng N, Lam V, Xie H, Wang M, Jin H, Xiong K, Liu C, Wright J, Young A (2003) GTI-2040, an antisense agent targeting the small subunit component (R2) of human ribonucleotide reductase, shows potent antitumor activity against a variety of tumors. Cancer Res 63: $2803-2811$

Marchetti A, Tinari N, Buttitta F, Chella A, Angeletti A, Sacco R, Mucilli F, Ullrich A, Iacobelli S (2002) Expression of 90K (Mac-2 BP) correlates with distant metastasis and predicts survival in stage I non-small cell lung cancer patients. Cancer Res 62: 2535-2539

Maulik G, Shrikhande A, Kijima T, Ma PC, Morrison PT, Salgia R (2002) Role of the hepatocyte growth factor receptor, c-Met, in oncogenesis and potential for therapeutic inhibition. Cytokine Growth Factor Rev 13: $41-59$

Medico E, Gentile A, Celso CL, Williams TA, Gambarotta G, Trusolino L, Comoglio PM (2001) Osteopontin is an autocrine mediator of hepatocyte growth factor-induced invasive growth. Cancer Res 61: 5861-5868

Menard S, Tagliabue E, Colnaghi MI (1998) The $67 \mathrm{kDa}$ laminin receptor as a prognostic factor in human cancer. Breast Cancer Res Treat 52: $137-145$

Modlin IM, Lye KD, Kidd MK (2003) A 5-decade analysis of 13, 715 carcinoid tumors. Cancer 97: 934-959

Nabeshima K, Shimao Y, Inoue T, Itoh H, Kataoka H, Koono M (1998) Hepatocyte growth factor/scatter factor induces not only scattering but also cohort migration of human colorectal-adenocarcinoma cells. Int $J$ Cancer 78: $750-759$

Nilsson O, Wangberg B, Kolby L, Schultz GS, Ahlman H (1995) Expression of transforming growth factor alpha and its receptor in human neuroendocrine tumours. Int J Cancer 60: 645-651

Nørsett KG, Laegreid A, Midelfart H, Yadetie F, Erlandsen SE, Falkmer S, Gronbech JE, Waldum HL, Komorowski J, Sandvik AK (2004) Gene expression based classification of gastric carcinoma. Cancer Lett 210: $227-237$

Öberg K (2000) State of the art and future prospects in the management of neuroendocrine tumors. Q J Nucl Med 44: 3-12

Peghini PL, Iwamoto M, Raffeld M, Chen YJ, Goebel SU, Serrano J, Jensen RT (2002) Overexpression of epidermal growth factor and hepatocyte growth factor receptors in a proportion of gastrinomas correlates with aggressive growth and lower curability. Clin Cancer Res 8: $2273-2285$

Pinheiro JC, Bates DM (2000) Mixed-effects models in S and S-PLUS. In Statistics and Computing Vol. XVI p 528 New York: Springer

$\mathrm{R}$ Development Core Team (2004) R: A language and environment for statistical computing. In $R$ Foundation for Statistical Computing Vienna, Austria, ISBN 3-900051-00-3, http://www.R-project.org

Ranson M (2004) Epidermal growth factor receptor tyrosine kinase inhibitors. Br J Cancer 90: 2250-2255

Reubi JC, Läderach U, Waser B, Gebbers J-O, Robberecht P, Laissue JA (2000) Vasoactive intestinal peptide/pituitary adenylate cyclase-activating peptide receptor subtypes in human tumors and their tissues of origin. Cancer Res 60: 3105-3112

Richards ML, Gauger P, Thompson NW, Giordano TJ (2004) Regression of type II gastric carcinoids in multiple endocrine neoplasia type 1 patients with Zollinger -Ellison syndrome after surgical excision of all gastrinomas. Word J Surg 28: 652-658

Sandvik AK, Cui G, Bakke I, Munkvold B, Waldum HL (2001) PACAP stimulates gastric acid secretion in the rat by inducing histamine release. Am J PhysiolGastrointest Liver Physiol 281: G997-G1003

Sherwood NM, Krueckl SL, McRory JE (2000) The origin and function of the pituitary adenylate cyclase-activating polypeptide (PACAP)/glucagon superfamily. Endocr Rev 21: 619-670 
Smith AM, Watson SA, Capline M, Clarke P, Griffin N, Varro A, Hardcastle JD (1998) Gastric carcinoid expresses the gastrin autocrine pathway. $\mathrm{Br} J$ Surg 85: $1285-1289$

Smyth GK (2004) Linear models and empirical bayes methods for assessing differential expression in microarray experiments. Statistical Application in Genetics and Molecular Biology Vol. 3, p 1, http://www.bepress.com/ sagmb/vol3/iss1/art3

Sridhar SS, Seymour L, Shepherd FA (2003) Inhibitors of epidermalgrowth-factor receptors: a review of clinical research with focus on nonsmall-cell lung cancer. Lancet Oncol 4: 397-406

Stålberg P, Lopez-Egido JR, Wang S, Gobl A, Oberg K, Skogseid B (2001) Differentially expressed cDNAs in PLCbeta3-induced tumor suppression in a human endocrine pancreatic tumor cell line: activation of the human mismatch repair protein 3 gene. Biochem Biophys Res Commun 281: 227-231

Storey JD, Tibshirani R (2003) Statistical significances for genomewide studies. Proc Natl Acad Sci USA 16: $9440-9445$

Talukder AH, Vadlamudi R, Mandal M, Kumar R (2000) Heregulin induces expression, DNA binding activity, transactivating functions of basic leucine zipper activating transcription factor 4. Cancer Res 60: 276-281

Townsend CM, Ishizuka J, Thompson JC (1993) Studies of growth regulation in a neuroendocrine cell line. Acta Oncol 32: 125-130

Toyama T, Iwase H, Yamashita H, Hara Y, Omoto Y, Sugiura H, Zhang Z, Fujii Y (2003) Reduced expression of the syk gene is correlated with poor prognosis in human breast cancer. Cancer Lett 189: 97 - 102

von Wichert G, Jehle PM, Hoeflich A, Koschnick S, Dralle H, Wolf E, Wiedenmann B, Boehm BO, Adler G, Seufferlein T (2000) Insulin-like growth factor-I is an autocrine regulator of chromogranin A secretion and growth in human neuroendocrine tumor cells. Cancer Res 60: 4573-4581

Waldum H, Brenna E, Kleveland PM, Sandvik AK (1995) Gastrin physiological and pathophysiological role: clinical consequences. Dig Dis 13: $25-38$
Watson SA, Clarke PA, Smith AM, Varro A, Michaeli D, Grimes S, Caplin M, Hardcastle JD (1998) Expression of CCKB/gastrin receptor isoforms in gastro-intestinal tumour cells. Int $\mathrm{J}$ Cancer 77: $572-577$

Wulbrand U, Wied M, Zofel P, Goke B, Arnold R, Fehmann H (1998) Growth factor receptor expression in human gastroenteropancreatic neuroendocrine tumours. Eur J Clin Invest 28: 1038-1049

Xie K (2001) Interleukin-8 and human cancer biology. Cytokine Growth Factor Rev 12: 375 - 391

Yadetie Y, Laegreid A, Bakke I, Kusnierczyk W, Komorowski J, Waldum HL, Sandvik AK (2003) Liver gene expression in rats in response to the peroxisome proliferator-activated receptor alpha agonist ciprofibrate. Physiol Genom 15: 9-19

Yang YH, Dudoit S, Luu P, Lin DM, Peng V, Ngai J, Speed TP (2002) Normalization of cDNA microarray data: a robust composite method addressing single and multiple slide systematic variation. Nucleic Acids Res 30: e15

Yee D (2002) The insulin-like growth factor system as a treatment target in breast cancer. Sem Oncol 29: 86-95

Zhang X, Yee D (2002) Insulin-like growth factor binding protein-1 (IGFBP1) inhibits breast cancer cell motility. Cancer Res 62(Suppl 11): $4369-4375$

Zhang X, Zhu T, Chen Y, Mertani HC, Lee KO, Lobie PE (2003) Human growth hormone-regulated HOXA1 is a human mammary epithelial oncogene. J Biol Chem 278: $7580-7590$

Zhou B, Yen Y (2001) Characterization of the human ribonucleotide reductase M2 subunit gene; genomic structure and promoter analyses. Cytogenet Cell Genet 95: 52 - 59

Zhou R, Skalli O (2000) Identification of cadherin-11 down-regulation as a common response of astrocytoma cells to transforming growth factoralpha. Differentiation 66: 165-172 